\title{
Eco-Friendly HPTLC Method for Simultaneous Analysis of Simvastatin and Ezetimibe in Pharmaceutical Preparations and Trying to Use Limonene as Eluent
}

\author{
Eldin $\mathrm{AB}^{1^{*}}$, Ismaiel $\mathrm{OA}^{2}$, Hassan $\mathrm{WE}^{2}$ and Shalaby $\mathrm{AA}^{2}$ \\ ${ }^{1}$ Sigma Pharmaceutical Industries, Zone 1, Moubarak Industrial City, Quesna Menoufia, Egypt \\ ${ }^{2}$ Pharmaceutical Analytical Chemistry, Faculty of Pharmacy, Zagazig University, Egypt
}

\begin{abstract}
In this study, a simple, rapid, sensitive and green High Performance Thin Layer chromatography (HPTLC) method was developed and validated for determination of Simvastatin and Ezetimibe in tablet dosage form. The method was

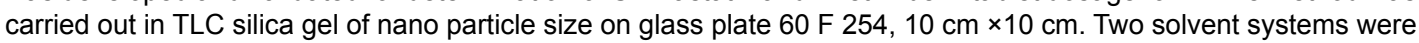
chosen according to the Green Analytical Chemistry (GAC) parameters. Acetone: Heptane: Isopropyl alcohol in the proportion of 10:10:5, (v/v/v) with Rf Value for Simvastatin and Ezetimibe was 0.513 and 0.312 respectively. The linear regression coefficients were 0.999 and 0.998 for Simvastatin and Ezetimibe with respect to peak area and height in the concentration range of $600-1500 \mathrm{ng} / \mathrm{spot}$ and $150-375 \mathrm{ng} / \mathrm{spot}$ respectively. To get greener solvent, heptane was replaced with limonene in the second elution system but this system could separate either Simvastatin or Ezetimibe solely in single preparations but could not separate both of them simultaneously because both of them has almost the same Rf. The linear regression coefficients were 0.998 and 0.995 for Simvastatin and Ezetimibe respectively with the same concentration range of the first system. TLC plates of nano sized particles offer sharper separations due to small particle size and narrow fractionation. Theoretical plate heights (h values) are considerably smaller than those of the standard TLC plate. In addition diffusion and - as a consequence -band broadening are much lower. Also shorter developing times and shorter migration distances: After only a few centimeters an optimal separation has been achieved.
\end{abstract}

Smaller samples of 0.01-0.1 $\mu \mathrm{l}$ (10-100 nanoliters). The samples applied are considerably smaller than with standard plates, thus it is possible to apply a large number of samples to a very small surface area, without samples interfering with each other. Finally increased detection sensitivity (nanogram level, hence nano plate). With fluorescence evaluation pico-gram quantities can be detected

Keywords: Green analytical chemistry; High performance thin layer chromatography; Limonene; Simvastatin; Ezetimibe

\section{Introduction}

Simvastatin (SIMV) is chemically 2,2-dimethylbutanoic $\operatorname{acid}(1 \mathrm{~S}, 3 \mathrm{R}, 7 \mathrm{~S}, 8 \mathrm{~S}, 8 \mathrm{aR})-1,2,3,7,8,8$ ahexahydro-3,7-dimethyl-8-[2[(2R,4R)-tetrahydro-6-oxo-2H-pyran-2-yl]ethyl]-1naphthalenyl ester [1] (Figure 1) SIMV competitively inhibit conversion of HMG-CoA to mevalonate, a rate limiting step in cholesterol synthesis [2]. Ezetimibe (EZMB), the first compound approved for lowering total and LDL-C levels through inhibiting cholesterol absorption in the small intestine and it is used primarily as adjunctive therapy with statins. Chemically it is 1-(4-fluorophenyl)-3(R)-[3- (4fluorophenyl)-3(S)-hydroxypropyl]4(S)-(4-hydroxyphenyl)-2-azetidinone (Figure 2). Few methods based on HPLC [3,4], LC-MS [5,6] and GC-MS [7] was reported earlier for the determination of simvastatin, ezitimibe or their combination.

TLC is the most simple and basic chromatographic procedure and is used for the separation of widely applicable compounds. TLC method has become useful as a technique due to its advantages of reliability in quantitation of analytes at various concentration reaching micro or nanogram levels and its cost effectiveness. Several samples can be analyzed using a small quantity of mobile phase. This reduces the time and cost of analysis. These advantages coordinate with the GAC parameters.

GAC parameters have been followed in developing the HPTLC method. Pfizer company has introduced medicinal chemistry solvent selection guide [8] including 3 categories of preferred solvents such as Water, Acetone, Ethanol, 2-Propanol,1-Propanol, Ethyl Acetate, Heptane, Isopropyl acetate, Methanol, 1-Butanol and t-Butanol followed by usable solvents and finally undesirable solvents. Three of the preferred solvents have been chosen for the first elution systems. Limonene is a biorenewable cycloterpene solvent coming from orange peel waste [9]. It was evaluated as a possible substitute for heptane in a greener separation system. In addition, it has been used as a green or bio-solvent for extraction of simvastatin, lovastatin and their hydroxyacid metabolite from plasma samples followed by direct injection of samples [10]. There are similar physic-chemical properties of limonene and heptane as shown in Table 1[11] but the double bonds of the limonene molecule allows for possible $\pi-\pi$ interactions with solutes rendering limonene slightly more polar than heptane giving

*Corresponding author: Eldin AB, Sigma Pharmaceutical Industries, Zone 1 Moubarak Industrial City, Quesna Menoufia, Egypt, Tel: 048 2590191; Fax: 048 2590198; E-mail: a.badr@sigma-pharm.com

Received July 27, 2015; Accepted September 15, 2015; Published September 18,2015

Citation: Eldin AB, Ismaiel OA, Hassan WE, Shalaby AA (2015) Eco-Friendly HPTLC Method for Simultaneous Analysis of Simvastatin and Ezetimibe in Pharmaceutical Preparations and Trying to Use Limonene as Eluent. Pharm Anal Acta 6: 417. doi:10.4172/21532435.1000417

Copyright: $\odot 2015$ Eldin AB, et al. This is an open-access article distributed under the terms of the Creative Commons Attribution License, which permits unrestricted use, distribution, and reproduction in any medium, provided the original author and source are credited. 
Citation: Eldin AB, Ismaiel OA, Hassan WE, Shalaby AA (2015) Eco-Friendly HPTLC Method for Simultaneous Analysis of Simvastatin and Ezetimibe in Pharmaceutical Preparations and Trying to Use Limonene as Eluent. Pharm Anal Acta 6: 417. doi:10.4172/21532435.1000417

Page 2 of 5

small differences in solute partition coefficients also this double bond is responsible for the darker background of the separation plate due to slight UV absorption properties. Through continuing research of the greenness of methods for the chromatographic determination of simvastatin and ezetimibe in their pharmaceutical preparations, an attempt was made to develop a novel, simple, rapid, and validated eco-friendly TLC-densitometry method, based on GAC parameters in addition to evaluating the possibility of using limonene as bio-solvent in the elution system. In all cases, nano sized TLC plate has been used to achieve minimum analysis time.

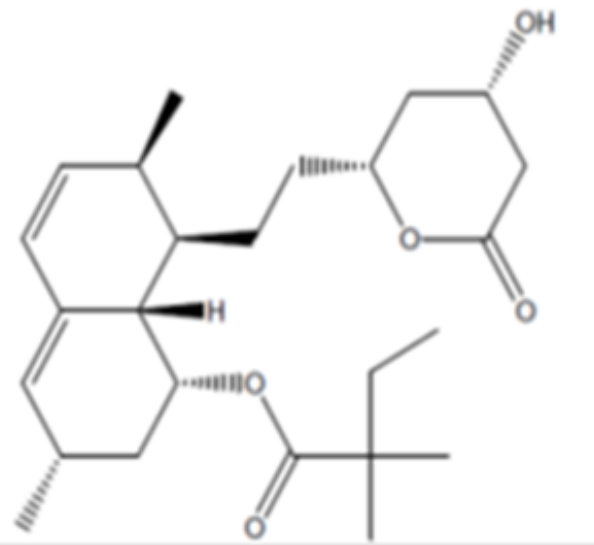

Figure 1: Chemical structure of Simvastatin.

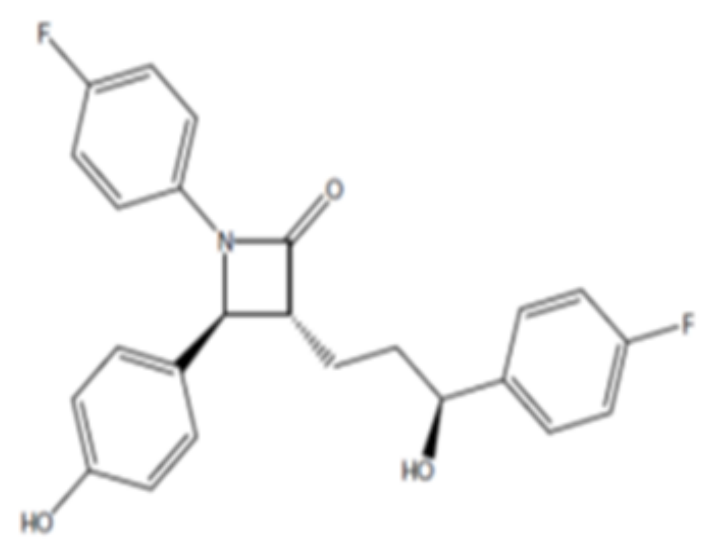

Figure 2: Chemical structure of Ezetimibe

\begin{tabular}{|c|c|c|c|}
\hline parameter & Unit & Heptane & Limonene \\
\hline Molecular weight & Dalton & 100 & 136 \\
\hline Density & $\mathrm{g} / \mathrm{cm} 3$ & 0.679 & 0.841 \\
\hline Octanol/water partition coefficient & ------ & 4.50 & 4.58 \\
\hline Water solubility at $25^{\circ} \mathrm{C}$ & Weight $\%$ & $0.00024 \%$ & $0.08 \%$ \\
\hline Methanol solubility at $25^{\circ} \mathrm{C}$ & Weight $\%$ & $29.7 \%$ & $32 \%$ \\
\hline Viscosity at $25^{\circ} \mathrm{C}$ & $\mathrm{CPs}$ & 0.389 & 0.923 \\
\hline Boiling point & ${ }^{\circ} \mathrm{C}$ & 98.4 & 178 \\
\hline UV Cut off wavelength & $\mathrm{nm}$ & 200 & 250 \\
\hline
\end{tabular}

Table1: Physico-chemical properties of heptane and limonene.

\section{Experimental}

\section{Apparatus}

An offline automatic sample applicator equipped with $100 \mu \mathrm{L}$ syringe (Camag Linomat 5, Switzerland) and plate scanner (Camag, Switzerland) was employed

for the TLC-densitometric analysis. Both of the applicator and the densitometer were controlled using winCATS-4 software (Camag, Switzerland). Nano silica gel glass TLC F254 plates, layer thickness $200 \mu \mathrm{m}$, part.No 08595 were obtained from Sigma-aldrich, Darmstadt, Germany.

\section{Reagents}

Ethanol, isopropanol, Ethyl acetate, heptane and limonine, were obtained from Sigma-aldrich, Darmstadt, Germany. All the reagents were of analytical grade.

placebo contains the same raw materials used in the formula production, were used. All materials are of pharmaceutical grade and include microcrystalline cellulose, calcium hydrogen phosphate, povidone $\mathrm{K} 30$, talc, magnesium stearate, croscarmellose sodium and colloidal silicon dioxide.

\section{Reference solutions}

Stock solutions of simvastatin and ezetimibe have been prepared then series of dilutions have been performed to obtains simvastatin standard solutions of $60-150 \mu \mathrm{g} / \mathrm{ml}$ range and ezetimibe standard solutions of $15-37.5 \mu \mathrm{g} / \mathrm{ml}$ range. Ethanol has been chosen as a solvent for all samples as it is widely accepted as a greener solvent.

\section{Samples}

The following medicines were analyzed: Eztrol $10 \mathrm{mg}$ tablets containing $10 \mathrm{mg}$ ezetimibe (schering plough), simvacor $40 \mathrm{mg}$ tablets containing $40 \mathrm{mg}$ simvastatin (Sigma pharmaceutical Ind.) and simvacor plus tablets containing $40 \mathrm{mg}$ simvastatin and $10 \mathrm{mg}$ ezetimibe (Sigma pharmaceutical Ind.).

\section{Sample preparation}

Samples of randomly selected tablets were crushed, mixed, dissolved and diluted to the appropriate volumes using ethanol as solvent. All samples were filtered through nylon sample filter (Whatman, $0.45 \mu \mathrm{m}$ ).

\section{Establishing TLC conditions}

Standard solutions were applied on Nano silica gel glass TLC F254 plates, $10 \times 10 \mathrm{~cm}$. Different volumes of the solutions (from 6 to 15 $\mu \mathrm{L}$ ) were applied to the plates, as $3 \mathrm{~mm}$ bands by means of a Linomat 5 automatic spray-on sample applicator equipped with a $100 \mu \mathrm{L}$ syringe. In all experiments, bands were spaced $2.0 \mathrm{~cm}$ apart and $1.5 \mathrm{~cm}$ from the bottom edge of the plate as was recommended in previous publication of similar application [12]. The two green mobile phases were tried. The first one composed of Acetone: Heptane: Isopropyl alcohol in the proportion of 10:10:5, $(\mathrm{v} / \mathrm{v} / \mathrm{v})$ while the second one composed of Acetone: Limonene: Isopropyl alcohol in the same proportion. Detection was carried out at $238 \mathrm{~nm}$. The plates were then developed to $8 \mathrm{~cm}$ with experimentally selected mobile phases in a TLC chamber, previously saturated with the mobile phase vapor for $15 \mathrm{~min}$ at room temperature.

For the distance of $8 \mathrm{~cm}$ the constituents were well separated in about $9 \mathrm{~min}$. After development, the TLC plates were dried in a current 
Citation: Eldin AB, Ismaiel OA, Hassan WE, Shalaby AA (2015) Eco-Friendly HPTLC Method for Simultaneous Analysis of Simvastatin and Ezetimibe in Pharmaceutical Preparations and Trying to Use Limonene as Eluent. Pharm Anal Acta 6: 417. doi:10.4172/21532435.1000417

Page 3 of 5

of air. Densitometric scanning to locate spots on the chromatograms was performed with a TLC Scanner 3, equipped with the deuterium light source, in linear reflectance/absorbance mode, controlled by CATS 4 Software resident in the system. The slit dimensions were $8 \times$ $0.45 \mathrm{~mm}$, the scanning speed $20 \mathrm{~mm} / \mathrm{s}$. For individual constituents, the retardation factors $\mathrm{Rf}$ were derived from the obtained densitograms.

\section{Calibration and validation}

Validation of the analytical method was carried out according to ICH guidelines for the two proposed systems to confirm reliability of the results [13].

System suitability criteria were determined [14] in order to assess the efficiency of separation. The specificity of the method was determined by comparing the chromatograms obtained from the test solutions containing simvastatin and ezetimibe with those obtained from placebo solutions and analyzing them for peaks interfering with the detection of active substances. The linearity was checked on six solutions of various concentrations varying from $600-1500 \mathrm{ng} / \mathrm{band}$ and 150-375 ng/band for simvastatin and ezetimibe respectively. Analysis was carried out as described and the integrated peak area was plotted versus concentration and the regression equation was calculated. Limits of detection (LOD) and quantitation (LOQ) were determined on the basic of the standard deviation of the response and slope of the straight lines, obtained from the linear regression equations as follow:

$$
\mathrm{LOD}=3.3 \times \mathrm{SD} / \mathrm{a} \text { and } \mathrm{LOQ}=10 \times \mathrm{SD} / \mathrm{a} \text {, }
$$

where $\mathrm{SD}$ is the standard deviation of the response and a is the slope of the calibration curve. The precision of the method was expressed as a consistence degree between the results of analyses carried out repeatedly. It was estimated using peak areas of individual constituents and relative standard deviation. Intermediate precision was determined by analyzing the same solutions on two different days.

The accuracy of the method was ascertained on the basis of recovery studies performed by standard addition within the range from $80 \%$ to $120 \%$ of the label claim. A known amount of each standard powder was mixed with samples of tablet powder, and these were then analyzed as described above.

\section{Results and Discussion}

\section{HPTLC method development and optimization}

Various developing systems of different compositions were tried and have been chosen according to green analytical chemistry aspects. The results were evaluated with respect to the efficiency of separation and the shape of separated bands.

Optimum resolution was obtained with System-1, composed of Acetone: Heptane: Isopropyl alcohol in the proportion of 10:10:5, $(\mathrm{v} / \mathrm{v} / \mathrm{v})$ as shown in Figure 3, while in system-2 Heptane was replaced by Limonene in the same proportion but in this system the $\mathrm{Rf}$ of both the active materials is almost the same so it could be used effectively for assay of preparations containing either simvastatin or ezitimibe as a single drug.

\section{Method validation}

System suitability: System suitability parameters have been investigated and recorded into Table 2 for the proposed two systems.

As mentioned above system-1 for simultaneous determination of both active materials while system- 2 could separate a single drug efficiently.

Specificity: The chromatograms of the placebo solutions did not show any peaks at the positions of the peaks of interest as shown in Figure 4. System-1 was efficient in separating both active principles simultaneously as shown in Figure 5, while in system-2, although it is greener but specificity has not been achieved because both materials has almost the same relative retention time so it has been used for separating each material in single drug preparations as shown in Figure 5. In addition, the double bond of limonene was responsible for a darker background.

Linearity: Linearity was established by least squares linear regression analysis of the calibration curve. The constructed calibration plots were linear over the concentration ranges $60-150 \mu \mathrm{g} / \mathrm{ml}$ and 15 $37.5 \mu \mathrm{g} / \mathrm{ml}$ for simvastatin and ezetimibe, respectively. Peak areas were plotted against their respective concentrations and linear regression analysis was performed on the resulting plots. The results are presented in Table 3.

Precision: The repeatability and intermediate precision results are summarized in Table 4. Method precision was investigated by injecting five tablet samples $(n=5)$ in duplicate. Intermediate precision (intraday) was investigated by injecting three samples $(\mathrm{n}=3)$.

Accuracy: The accuracy (closeness to true value) was determined as percent recovery for spiked samples injected in triplicate of placebo solutions at concentration levels ranged at 80,100 , and $120 \%$ of the method level. The percentage recoveries were ranged from (99.3$101.3 \%$ ) with \% RSD within $2.0 \%$ for both 2 systems, which indicated the accuracy of the proposed method as shown in Table 5.

\section{Conclusion}

In this study, two systems have been tried for separation of simvastatin and ezetimibe. Both systems have been formulated according to green analytical chemistry aspects.

Nano-sized silica on glass plate has been used to achieve dramatic reduction in analysis time and mobile phase consumption. System-1 could be used efficiently for separation of both active materials

\begin{tabular}{|c|c|c|c|c|c|c|}
\hline Item & Resolution (Rs) & $\begin{array}{l}\text { Selectivity } \\
\text { (ठ) }\end{array}$ & $\begin{array}{l}\text { Tailing Factor } \\
\text { (t) }\end{array}$ & $\begin{array}{l}\text { Capacity factor } \\
\text { (K) }\end{array}$ & $\begin{array}{c}\text { Number of theoretical } \\
\text { plates }(\mathrm{N})\end{array}$ & $\begin{array}{l}\text { Height eq. to theoretical } \\
\text { plate (HETP) }\end{array}$ \\
\hline Reference value & $>1.5$ & $>1.0$ & About 1 & $1-10$ & $\begin{array}{l}\text { Increase with efficient } \\
\text { separation }\end{array}$ & $\begin{array}{c}\text { The smaller the value the } \\
\text { higher the efficiency }\end{array}$ \\
\hline \multicolumn{7}{|c|}{ Ezetimibe } \\
\hline System-1 & 2.1 & 1.05 & 0.96 & 2.3 & 3240 & $1.21 \times 10^{-3}$ \\
\hline System-2 & 1.8 & 1.02 & 1.02 & 1.9 & 2996 & $2.6 \times 10^{-3}$ \\
\hline \multicolumn{7}{|c|}{ Simvastatin } \\
\hline System-1 & 2.3 & 1.1 & 1.03 & 3.2 & 3589 & $1.23 \times 10^{-3}$ \\
\hline System-2 & 1.9 & 1.03 & 1.05 & 2.1 & 3033 & $2.4 \times 10^{-3}$ \\
\hline
\end{tabular}

Table2: System suitability parameters of the proposed TLC-densitometric assays 
Citation: Eldin AB, Ismaiel OA, Hassan WE, Shalaby AA (2015) Eco-Friendly HPTLC Method for Simultaneous Analysis of Simvastatin and Ezetimibe in Pharmaceutical Preparations and Trying to Use Limonene as Eluent. Pharm Anal Acta 6: 417. doi:10.4172/21532435.1000417

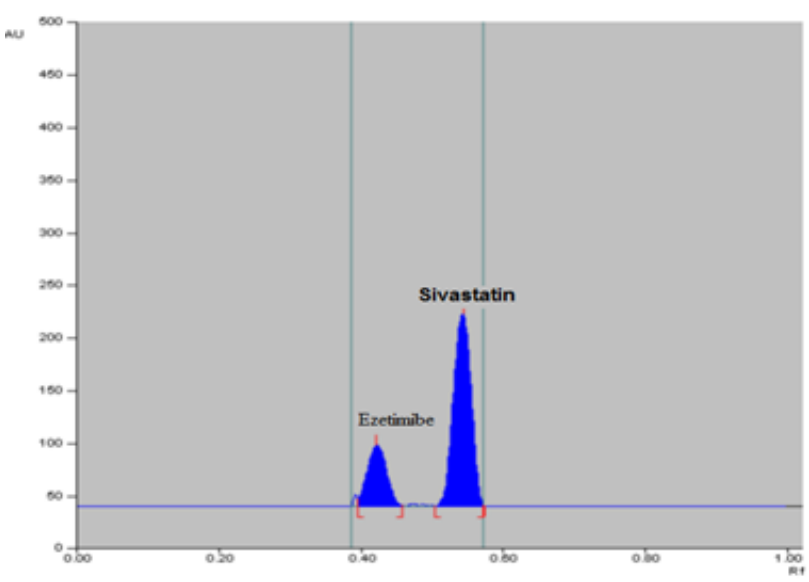

Figure 3: Densitogram of standard substances: simvastatin and ezetimibe obtained directly from chromatogram.

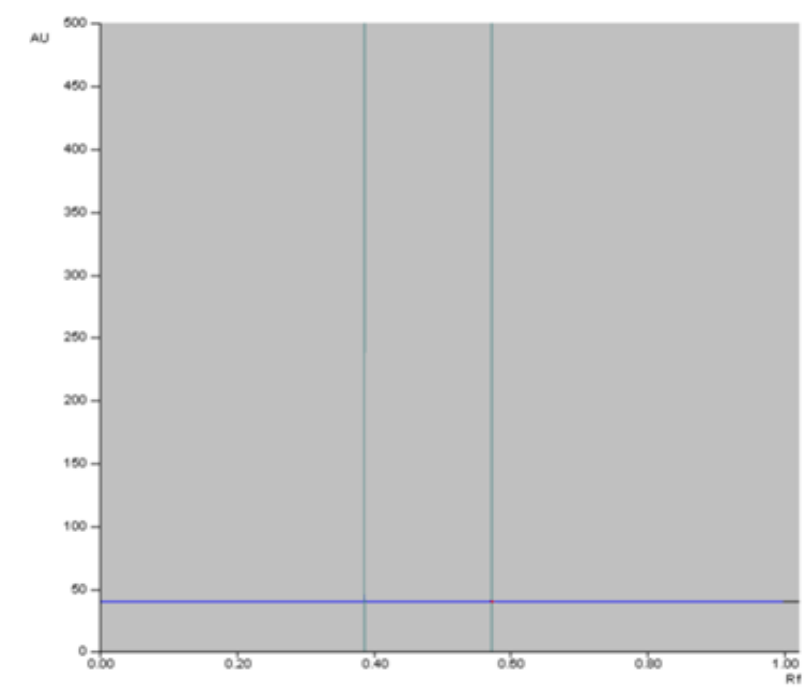

Figure 4: The placebo solutions did not show any peaks at the positions of peak of interest.

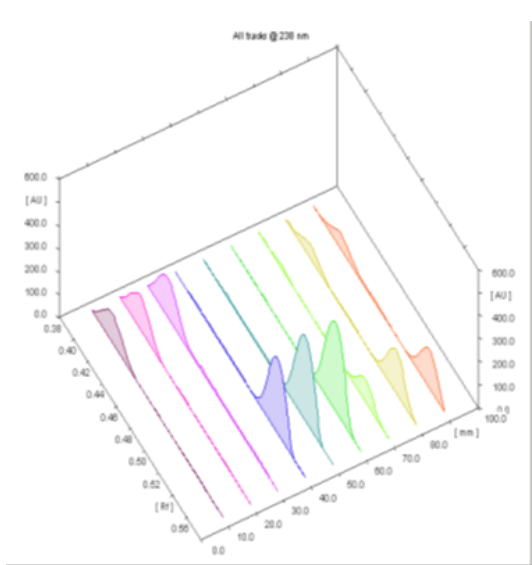

Figure 5: System-1 efficient in separating simvastatin and ezetimibe simultaneously.

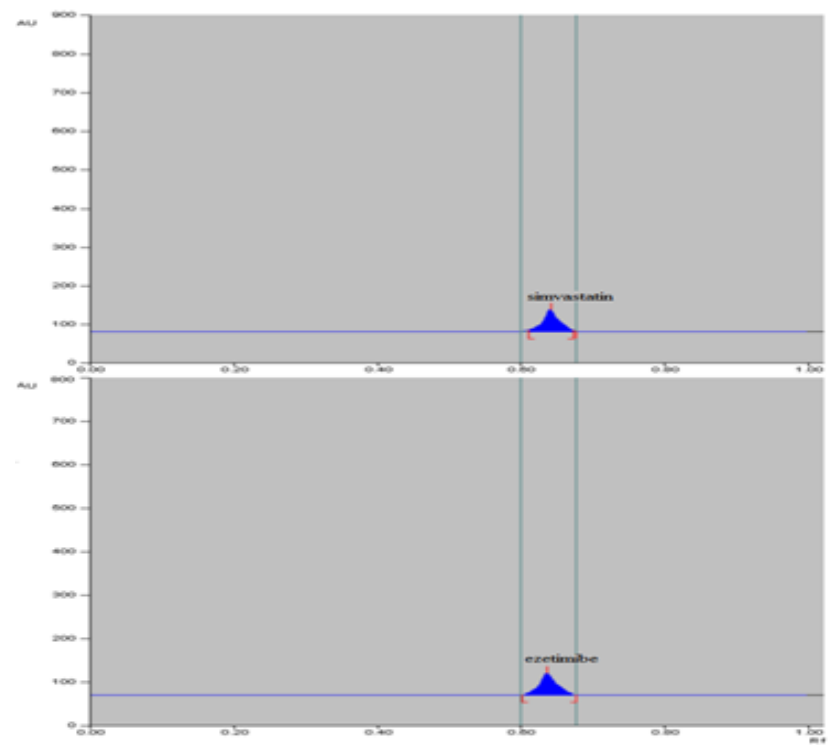

Figure 6: System-2, although greener but efficient in separating simvastatin and ezetimibe in single drug preparation.

\begin{tabular}{|c|c|c|c|c|c|c|c|c|}
\hline Item & Calibration range $(\mu \mathrm{g} / \mathrm{ml})$ & Correlation coefficient & Slope & $\begin{array}{l}\text { Slope } 95 \% \text { confidence } \\
\text { interval for the slope }\end{array}$ & intercept & $\begin{array}{l}\text { Slope } 95 \% \quad \text { confidence } \\
\text { interval for the intercepta }\end{array}$ & $\begin{array}{l}\operatorname{LOQ}(\mu \mathrm{g} \\
/ \mathrm{ml})\end{array}$ & $\begin{array}{l}\text { LOD }(\mu \mathrm{g} \\
/ \mathrm{ml})\end{array}$ \\
\hline \multicolumn{9}{|c|}{ Simvastatin } \\
\hline System-1 & \multirow[t]{2}{*}{$60-150$} & 0.999 & 23.709 & \pm 0.0387 & 6978.43 & \pm 2.094 & 1.23 & 1.05 \\
\hline System-2 & & 0.999 & 23.227 & \pm 0.0765 & 946.33 & \pm 2.082 & 1.96 & 1.15 \\
\hline \multicolumn{9}{|l|}{ Ezetimibe } \\
\hline System-1 & \multirow[t]{2}{*}{$15-37.5$} & 0.999 & 54.293 & \pm 0.0935 & 2834.5 & \pm 2.094 & 1.03 & 0.95 \\
\hline System-2 & & 0.995 & 105.35 & \pm 0.0396 & -567.7 & \pm 2.082 & 1.84 & 1.31 \\
\hline
\end{tabular}

Table3: Summary for the regression equation parameters of the proposed TLC-densitometric method. 
Citation: Eldin AB, Ismaiel OA, Hassan WE, Shalaby AA (2015) Eco-Friendly HPTLC Method for Simultaneous Analysis of Simvastatin and Ezetimibe in Pharmaceutical Preparations and Trying to Use Limonene as Eluent. Pharm Anal Acta 6: 417. doi:10.4172/21532435.1000417

Page 5 of 5

\begin{tabular}{|c|c|c|c|c|}
\hline \multirow[t]{2}{*}{ Item } & \multicolumn{2}{|c|}{ Repeatability } & \multicolumn{2}{|c|}{ intermediate precision } \\
\hline & Mean \pm SD & RSD (\%) & Mean \pm SD & RSD (\%) \\
\hline \multicolumn{5}{|c|}{ Simvastatin } \\
\hline System-1 & $99.51 \pm 0.44$ & 0.45 & $100.21 \pm 0.51$ & 0.51 \\
\hline System-2 & $100.32 \pm 0.96$ & 0.96 & $100.88 \pm 0.85$ & 0.84 \\
\hline \multicolumn{5}{|c|}{ Ezetimibe } \\
\hline System-1 & $100.23 \pm 0.73$ & 0.73 & $99.95 \pm 0.65$ & 0.66 \\
\hline System-2 & $98.98 \pm 0.97$ & 0.98 & $99.96 \pm 0.91$ & 0.92 \\
\hline
\end{tabular}

Table 4: Repeatability and intermediate precision data.

\begin{tabular}{|c|c|c|c|c|}
\hline \multirow[t]{2}{*}{ Level (\%) } & \multicolumn{2}{|c|}{ System-1 } & \multicolumn{2}{|c|}{ System-2 } \\
\hline & $\%$ Recovery & RSD (\%) & $\%$ Recovery & RSD (\%) \\
\hline \multicolumn{5}{|c|}{ Simvastatin } \\
\hline 80 & 99.4 & 1.09 & 101.3 & 1.48 \\
\hline 100 & 100.5 & 0.73 & 101.2 & 1.41 \\
\hline 120 & 101.1 & 0.64 & 100.9 & 1.34 \\
\hline Average & \multicolumn{2}{|c|}{$100.33 \%$} & \multicolumn{2}{|c|}{$101.13 \%$} \\
\hline \multicolumn{5}{|c|}{ Ezetimibe } \\
\hline 80 & 100.4 & 1.02 & 101.3 & 1.38 \\
\hline 100 & 99.3 & 0.56 & 100.8 & 1.22 \\
\hline 120 & 100.5 & 0.49 & 101.1 & 1.44 \\
\hline Average & \multicolumn{2}{|c|}{$100.1 \%$} & \multicolumn{2}{|c|}{$101.06 \%$} \\
\hline
\end{tabular}

Table 5: Estimation of the accuracy as an item for validation of the proposed HPTLC method $(n=3)$.

simultaneously while system-2 could be used only for separation of each material but in single drug preparation only. Usage of limonene as an eluent is quite new green approach in chromatography but more investigations are required to achieve more efficient separation systems using this natural and renewable material.

\section{References}

1. Moffat AC, Osselton DM, Widdop B (2004) Clarke's Analysis of Drugs and Poisons (3rd Edn) Pharmaceutical Press, London.

2. Brunton LL, Lazo JS, Parker KL (2006) Goodman and Gilman's, The Pharmacological Basis of Therapeutics, (11th edn) The McGraw Hill Co.

3. Muhammad Ashfaq, Islam Ullahkhan, Syed Shanaz Qutab, Syed Naeemrazzaq (2007) HPLC determination of ezetimibe and simvastatin in pharmaceutical formulations. J Chil Chem Soc 52: 1220-1223.

4. Seshukumar Devu, Abhishek Gupta, Kona S Srinivas, Ravi Shankar Gupta, Vinod Prasad Semwal (2012) Development and Validation of Stability Indicating RP-UPLC Method for Simultaneous Determination in Fixed Dose Combination of Ezetimibe and Simvastatin. J Chromat Separation Techniq 3.

5. Srinivasu MK, Narasaraju A, Omreddy G (2002) Determination of Lovastatin and Simvastatin in pharmaceutical dosage forms by MEKC. J Pharm Biomed Ana 29: 715-721.

6. Yang H, Feng $\mathrm{Y}$, Luan $\mathrm{Y}(2003)$ Determination of simvastatin in human plasma by liquid chromatography-mass spectrometry. J Chromatogr B Analyt Technol Biomed Life Sci 785: 369-375.
7. Morris MJ, Gilbert JD, Hsieh JY, Matuszewski BK, Ramjit HG, et al. (1993) Determination of the HMG-CoA reductase inhibitors simvastatin, lovastatin and pravastatin in plasma by gas chromatography/chemical ionization mass spectrometry. Biol Mass Spectrum 22: 1-8.

8. Dunn PJ, Perry DA, et al. (2008) Pfizer solvent selection guide, Green chemistry 9: 31-36.

9. Karine Faure, Elodie Bouju, Pauline Suchet, Alain Berthod (2013) Use of Limonene in Countercurrent Chromatography: A Green Alkane Substitute. Anal Chem 85: 4644-4650.

10. David V, Cheregi M, Medvedovici A (2013) Alternative sample diluents in bioanalytical LC-MS. Bioanalysis 5: 3051-3061.

11. Lord Kelvin, Michael Faraday, John Dalton, Robert Boyle (2015) Handbook of chemistry and physics ( $96^{\text {th }}$ edn) CRC press

12. Baghdady YZ, Al-Ghobashy MA, Abdel-Aleem A-AE, Weshahy SA (2013) Spectrophotometric and TLC-densitometric methods for the simultaneous determination of Ezetimibe and Atorvastatin calcium. J Adv Res 4: 51-59.

13. (2005) International Conference on Harmonization. Validation of analytical procedure methodology ICH Q2 (R1).

14. (2015) The United States Pharmacopoeia (USP 38): 621 Chromatography. 